\title{
sciendo
}

\section{Rethinking Monolithic Pathways to Success and Talent Identification: The Case of the Women's Japanese Volleyball Team and Why Height is Not Everything}

\author{
by \\ Jorge Vargas ${ }^{1}$, Manuel Loureiro ${ }^{1}$, Pantelis T. Nikolaidis ${ }^{2}$, Beat Knechtle ${ }^{3}$, \\ Lorenzo Laporta ${ }^{1}$, Rui Marcelino ${ }^{4}$, Jose Afonso ${ }^{1}$
}

\begin{abstract}
The aim of the present study was to analyse the Japanese National Women's Volleyball Team and to identify items differentiating it from other teams. All fifteen matches between the six National Teams (i.e., Japan, Brazil, China, Belgium, Turkey and Russia) competing at the Women's Volleyball World Grand Prix Finals of 2014 were analyzed, in a total of 56 sets and 7,176 situations of ball possession. Data suggested the existence of differences between Japan's and the other five teams' gameplay, namely the likelihood of more gameplay with utilization of the float jump serve (20.42; \pm $3.79 \%$, very large magnitude) and attack tempo $2(61.89 ; \pm 29.67 \%$, large magnitude), while exhibiting less gameplay with zero blockers opposing the attack $(-42.06 ; \pm 21.28 \%$, large magnitude). Based on these findings, it was concluded that sports success could be achieved even when a core feature of mainstream performance models (e.g., height in volleyball) was lacking.
\end{abstract}

Key words: performance, expertise, talent identification, match analysis, volleyball.

\section{Introduction}

Elite-level sport attracts considerable media attention, and has important economic and political consequences. Allied with the human appeal for transcendence (Lehmann and Kristensen, 2014), this fascination with sport has generated a wide body of research on the paths to sports expertise (Moesch et al., 2013). Emerging from this, the field of talent identification, development, and selection (TIDS) has merited broad attention from the scientific community (Vaeyens et al., 2009). Regardless of following strict deliberate practice (Macnamara et al., 2014) or alternative approaches to expertise (Kulasegaram et al., 2013), TIDS programs aim at the early signalling of features suggesting potential for achieving expert performance levels (Leite et al., 2009). The reasoning is that early identification of talent may assist sport systems in providing them with greater support and training conditions from an early stage, hopefully translating into optimal performance later on (Pankhurst et al., 2013). TIDS programs therefore follow a backwards logic: first, they identify the factors behind success at the highest levels of performance; then, they attempt to understand how stable and predictable those factors are in time (Ko et al., 2003).

Notwithstanding TIDS programs' objectives, their efficacy has been questioned. Namely, the inconsistencies between the different

1 - Faculty of Sport, University of Porto, Porto, Portugal.

2 - Exercise Physiology Laboratory, Nikaia, Greece.

3 - Institute of Primary Care, University of Zurich, Zurich, Switzerland.

4 - Research Center in Sports Sciences, Health and Human Development, Vila Real, Portugal. 
approaches, the lack of serious thought with regard to psychosocial variables, and the reduced rates of effectiveness have been highlighted (Ackerman, 2014). In sports such as volleyball, height is considered a core factor for playing at the highest levels (Nikolaidis et al., 2015a, 2015b; Sheppard et al., 2011). As height is a relatively stable feature and presents predictable evolution in time (Cole and Wright, 2011), attempts have been made to predict it early in the players' development (Beunen et al., 2010). This constitutes a perfect example of a physical feature that may overwhelm all other characteristics and thereby culminate in simplistic models. Hence, height will be the main point for our analysis, as the literature suggests that this factor is required for achieving elite levels of practice and playing (Martín-Matillas et al., 2014), and TIDS programs applied to volleyball usually underline the importance of this feature (Gabbett et al., 2007), with few exceptions demonstrating that it may not discriminate between talented players (Pion et al., 2015).

In line with the perspective of multiple paths towards sports expertise and the need to reconsider how TIDS programs are conceptualized (Vaeyens et al., 2009), we believe it is possible to find examples of volleyball teams performing at the highest level despite being considerably shorter than their opponents. Finding even one such an example would suffice to provide evidence for the need to recognize alternative TIDS criteria and models. In fact, not much can be done to improve individual height, while demographic variation will impose limits and certain countries will have natural advantages over others (Grasgruber et al., 2014). Nonetheless, the possibility of following different paths and of compensating for the lack of one strong predictor of success through other means delivers a powerful message. For example, research on motor learning has highlighted the role of eye-hand coordination and depth perception in expert performance (Neggers and Bekkering, 2002), and it may deeply influence the quality of game actions (Costa et al., 2014). This becomes even more relevant when considering that specific complex reaction time and speed of movement are paramount for performance (Mroczek et al., 2013; Nuri et al., 2013).

Here, our analysis will focus on the
Japanese National Women's Volleyball Team. In the FIVB ranking, they were placed $4^{\text {th }}$ in Adults and $3^{\text {rd }}$ in Junior and Youth (www.fivb.org/en/volleyball/index.asp; accessed on 2 December 2014), denoting systematic performance among the best in official international competitions. In the 2014 edition of the World Grand Prix, a reputed competition in which the best 28 national teams worldwide participated, Japan placed $2^{\text {nd }}$ in the finals. However, Japan ranked $27^{\text {th }}$ for average height (tied with Thailand) out of 28 teams, with a mean value of $174 \pm 8 \mathrm{~cm}$ (mean \pm standard deviation). The tallest team (Netherlands), in contrast, had an average height of $187 \pm 6 \mathrm{~cm}$. Only six out of 28 teams had an average height below $180 \mathrm{~cm}$. Consequently, it is legitimate to ask what factors assisted Japan in obtaining regular elite-level performances despite the lack of elite-level height. Such knowledge might aid in outlining alternate models for TIDS.

Therefore, the purpose of the present study was to analyse the Japanese National Women's Volleyball Team and to identify items differentiating it from the other teams. Potentially, identified factors will assist in establishing new avenues for TIDS in volleyball. Furthermore, this might inform TIDS in general, illustrating that several paths are possible to achieve elite performance.

\section{Methods}

\section{Participants}

All fifteen matches between the six National Teams competing at the Women's Volleyball World Grand Prix Finals of 2014 were analysed, totalling 56 sets and 7176 situations of ball possession. Participating teams were Japan, Brazil $(182 \pm 7 \mathrm{~cm})$, China $(186 \pm 7 \mathrm{~cm})$, Belgium $(184 \pm 6 \mathrm{~cm})$, Turkey $(186 \pm 7 \mathrm{~cm})$, and Russia (186 $\pm 8 \mathrm{~cm}$ ). The local University Ethics Committee provided institutional approval for this study.

\section{Measures}

The matches were recorded and broadcast in high-definition (1080 p) on the Laola.tv website. The viewpoint was placed laterally, aligned with the net, and with the camera turning to focus mostly on the team in possession of the ball.

\section{Procedures}

Game complex consisted of five categories: a) Complex I, "side-out" or attack after serve- 
reception, comprising the actions of serve reception, attack setting and attack (Palao and Ahrabi-Fard, 2011); b) Complex II, "side-out transition" or "counter-attack", comprising the serve, attack defense, counter-attack setting, and counter-attack (Costa et al., 2012); c) Complex III, "transition" or "counter-attack of counter-attack", including counter-attack defense, counter-attack setting, and counter-attack (Palao et al., 2004); d) Complex IV, "attack coverage", including defense after deflection on the opponent's block, setting from attack coverage and counter-attack (Laporta et al., 2015); and e) Complex $V$, including "freeball" and "downball", whenever the opponent struggled to build the attack and an easy ball could be expected in anticipation (Gil et al., 2011).

Setter's row allowed identification of whether the setter was in the front row (positions 2,3 or 4 ) or in the back row (positions 1, 5 or 6). When in the front row, the setter had two attackers also in the front row; when in the back row, the setter had three attackers available in the front. Therefore, this factor was likely to change the dynamics of the attack (Palao and AhrabiFard, 2011).

For the serve type we adapted the classification proposed by Costa et al. (2012), establishing three categories: a) jump serve (that implied ball rotation); $b$ ) float jump serve (without ball rotation); and c) ground serve (serve without jumping). Analysis of serve trajectory considered three beginning points (behind the official zones 1, 5 and 6) and six endpoints, corresponding to the six official game zones. Therefore, trajectories were identified using two numbers. For example, 56 meant a serve from zone 5 towards zone 6 . Since short serves (e.g., those directed towards zones 2, 3, and 4) were reduced in number (26 occurrences out of 2423 serves, roughly 1.07\%), we decided to group them together; hence, these will be merely reported as ' $S$ ' (for 'short').

Setting zone was divided into A (all attack options available), B (middle-player could still attack, but some attack combinations were not possible to execute, e.g. plays involving the crossing of attackers), and C (only high sets towards the extremities of the court or to the defensive zone were available) (Palao and AhrabiFard, 2011).

Attack zone comprised the six zones of the court as defined by the FIVB, numbered 1 to 6 counter-clockwise. For attack tempo we followed the categorization of Afonso et al. (2010): a) tempo 1 (the attacker jumped during or slightly after the set); $b$ ) tempo $2 \mathrm{Q}$ (the attacker took two steps after the set); $c$ ) tempo $2 S$ (the attacker took three steps after the set); and $d$ ) tempo 3 (the attacker waited after the set, and only used a three-step approach).

According to Papadimitriou et al. (2004) attack combination or play was defined as the intentional collaboration with more than one player connected in time and space to execute the proposed goals. We adapted the work of Afonso and Mesquita (2007): a) simple play (middleattacker attacked tempo 1, remaining players attacked tempos 2 or 3 in their positions); $b$ ) zone overload (middle-attacker attacked first tempo and the attacker nearest to him attacked first or second tempo in a proximal space); and $c$ ) crossing (one of the wing-hitters crossed behind the middle-attacker to attack in a more interior position).

For analysis of attack efficacy we used an adaptation of the categorization proposed by Palao and Ahrabi-Fard (2011), evaluating the attack in relation to its success and to the options that the opponent had for counterattacking: a) error $(0)$; b) all team attack options $(1)$; c) middle attacker could not attack (2); d) only high sets towards the extremities of the court available or ball returned directly towards the attacker's court (3); and e) point (4).

For block opposition we simplified the categorization of Afonso and Mesquita (2011). The following categories were considered: a) noblocking (B0); b) single block (B1); c) double block (B2), broken double block (B2B); and d) triple block (B3).

Number of defensive lines consisted of the number of imaginary lines formed by groups of players (or, occasionally, only one player), starting from the net to the endline.

\section{Statistical analysis}

Descriptive statistics were used to inform of the frequency of occurrence of each variable. A comparison between performance of the Japanese team and the other teams (considered as average values of Brazil, China, Belgium, Turkey and Russia) was assessed via standardized mean differences, considered as the effect sizes (ES), computed with pooled variance and respective 
90\% confidence intervals (CI) (Hopkins et al., 2009; Maszczyk et al., 2012). Data were analysed for practical significance using magnitude-based inferences. We used this quantitative approach because traditional statistic approaches often did not indicate the magnitude of an effect, which was typically more relevant for athletic performance than any statistically significance effect (Hopkins et al., 2009). To reduce bias, raw values from all the variables were normalized to the total number of executions performed by the respective team. Threshold values for ES were $>0.2$ (small), $>0.6$ (moderate), $>1.2$ (large) and $>2$ (very large). Uncertainty in each effect was expressed as $90 \%$ confidence limits and as probabilities that the true difference was substantially positive and negative. These probabilities were used to make qualitative probabilistic mechanistic inferences about the true differences: if the probabilities of the differences were substantially greater or smaller than the smallest worthwhile change $(0.2$ $x$ baseline between-teams SD); the differences were reported following the scale: $>5 \%$, unclear; $25-75 \%$, possible; $75-99 \%$, very likely; $>99 \%$, most likely.

\section{Reliability analysis}

Reliability of the observation and coding of game variables were calculated using Cohen's Kappa. The main observer was a level III volleyball coach with several years of experience in the sport. Intra-observer reliability was conducted one month after the initial observation of the plays. Inter-observer reliability included the observation of a set of plays by an independent observer who was also an experienced volleyball coach. In both cases, 1,335 plays were reanalysed, corresponding to $18.60 \%$ of the sample. For intraobserver reliability, Kappa ranged from 0.803 to 0.980. Inter-observer reliability was conducted after re-categorization of some variables, and therefore provided superior values, ranging from 0.913 to 1.000 . Thus, all values exceeded the threshold of 0.75 suggested in the literature (Fleiss et al., 2003).

\section{Results}

Descriptive data is presented in the appendix. Here, we focused on comparative analyses. Data suggested that there were differences between the gameplay of Japan and of the other teams. Results showed that Japan was very likely to use $(-12.07 ; \pm 7.34 \%)$ ( $\%$ of difference in means; $\pm 90 \% \mathrm{CL}$ ) lower gameplays in complex III (transition), with moderate magnitude, and likely $(11.43 ; \pm 17.14 \%)$ to use higher gameplays in complex V (freeball or downball), with small magnitude in comparison to the other teams (Figure 1).

Data further revealed that the Japanese team was most likely to use $(27.12 ; \pm 11.37 \%)$ higher gameplays with the setter in the front row, with small magnitude, in comparison with the other teams. Conversely, Japan was most likely to use $(-21.10 ; \pm 7.63 \%)$ lower gameplays with the setter in the back row, with moderate magnitude. Japan also seemed to have an improved quality of the first contact, as their team was likely to play $(4.48 ; \pm 4.03 \%)$ more gameplays in setting zone A than their opponents, albeit with small magnitude.

With regard to the serve type, the Japanese team was most likely to utilize a float jump serve $(20.42 ; \pm 3.79 \%$, very large magnitude), while very unlikely to use the ground serve ($98.84 ; \pm 0.89 \%$, very large magnitude) or the power jump serve $(-98.58 ; \pm 5.74 \%$, very large magnitude) as often as their opponents (Figure 2).

As for the serve trajectory, few differences were apparent between Japan and the remaining teams. Still, it is possible to highlight that Japan was less likely to use serves from position 5 towards position $5(-75.67 ; \pm 45-59 \%$, large magnitude), and very likely $(-80.02 ; \pm 17.98 \%$, very large magnitude) to use lower gameplays when they served from position 5 towards position 6 .

Concerning the attack zone, Japan was most likely $(-78.57 ; \pm 6.53 \%$, very large magnitude) to use lower gameplays with attack through zone 1 , while very likely to use $(13.09 ; \pm 5.56 \%$, moderate magnitude) higher gameplays deploying attacks through zone 2 (Figure 3).

Analysis of attack tempo revealed that Japan was most likely $(61.89 ; \pm 29.67 \%$, large magnitude) to attack more frequently using tempo 2 , while very likely $(-42.90 ; \pm 23.97 \%$, large magnitude) to produce lower gameplays using tempo 1 , and less likely $(-15.06 ; \pm 13.72 \%$, moderate magnitude) to use tempo 3 . With regard to attack combo, the Japanese team was very likely $(6.62 ; \pm 4.03 \%$, moderate magnitude) to produce higher gameplays using simple plays, in comparison with their opponents. Conversely, 
Japan was likely $(-53.46 ; \pm 43.55 \%$, moderate magnitude) to use lower frequencies of plays involving the zone overload when attacking. Data for attack efficacy provided unclear trends (Figure 4). As for block opposition, the Japanese team was very likely $(-42.06 ; \pm 21.28 \%$, large magnitude) to have a lower frequency of gameplays having zero blockers opposing the attack.

Finally, Japan was less likely $(-7.55 ; \pm 7.64 \%$, moderate magnitude) to use defensive systems composed of two lines of defence.
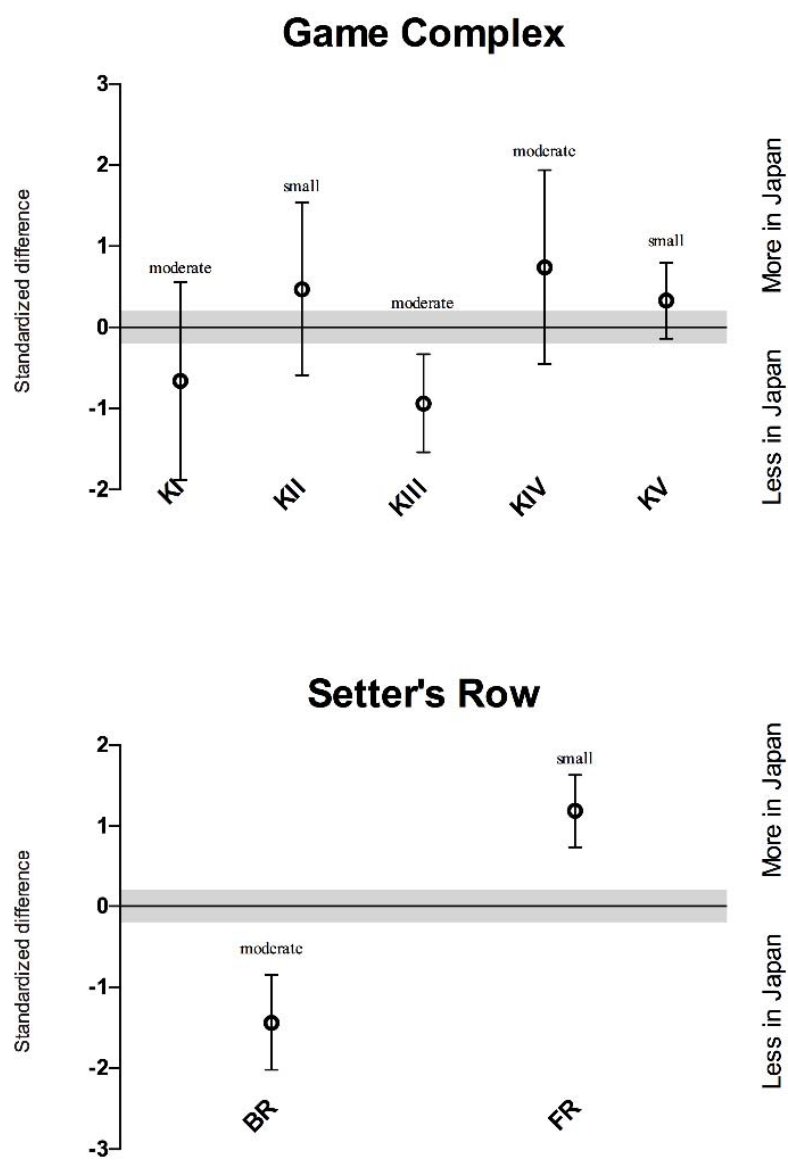

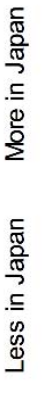

Setting Zone

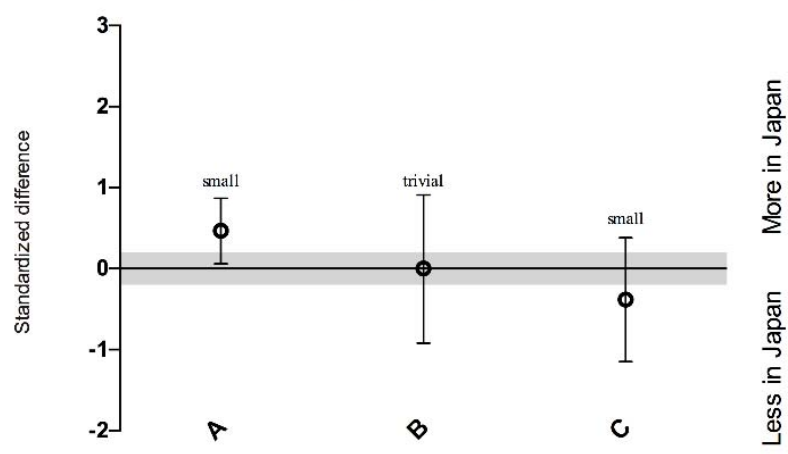

Figure 1

Game complex, setter's row and setting zone 

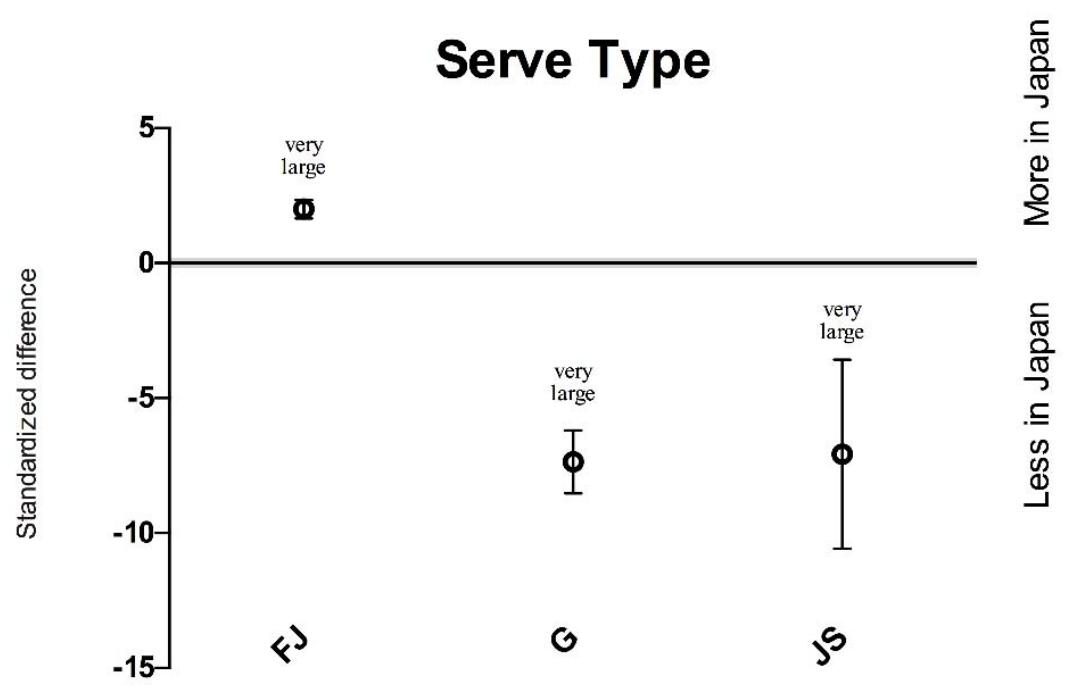

\section{Serve Trajectory}

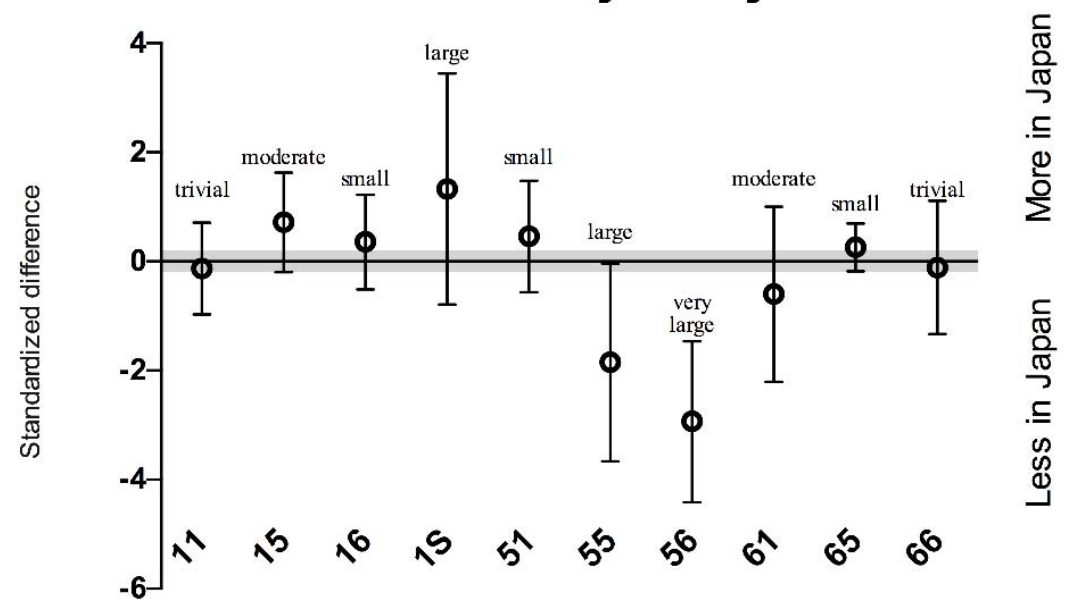

Figure 2

Serve type and trajectory 

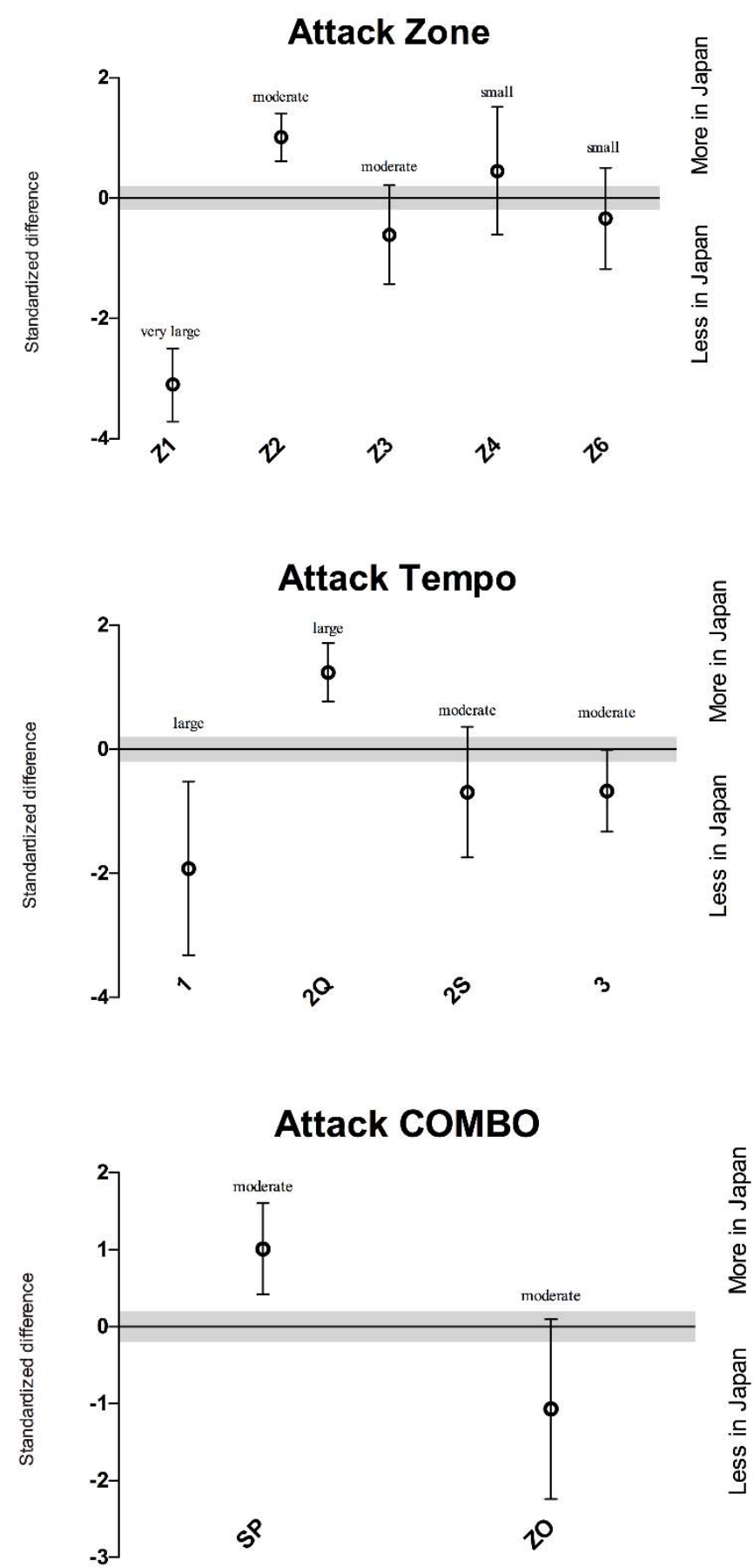

Figure 3

Attack zone, tempo, and combination 

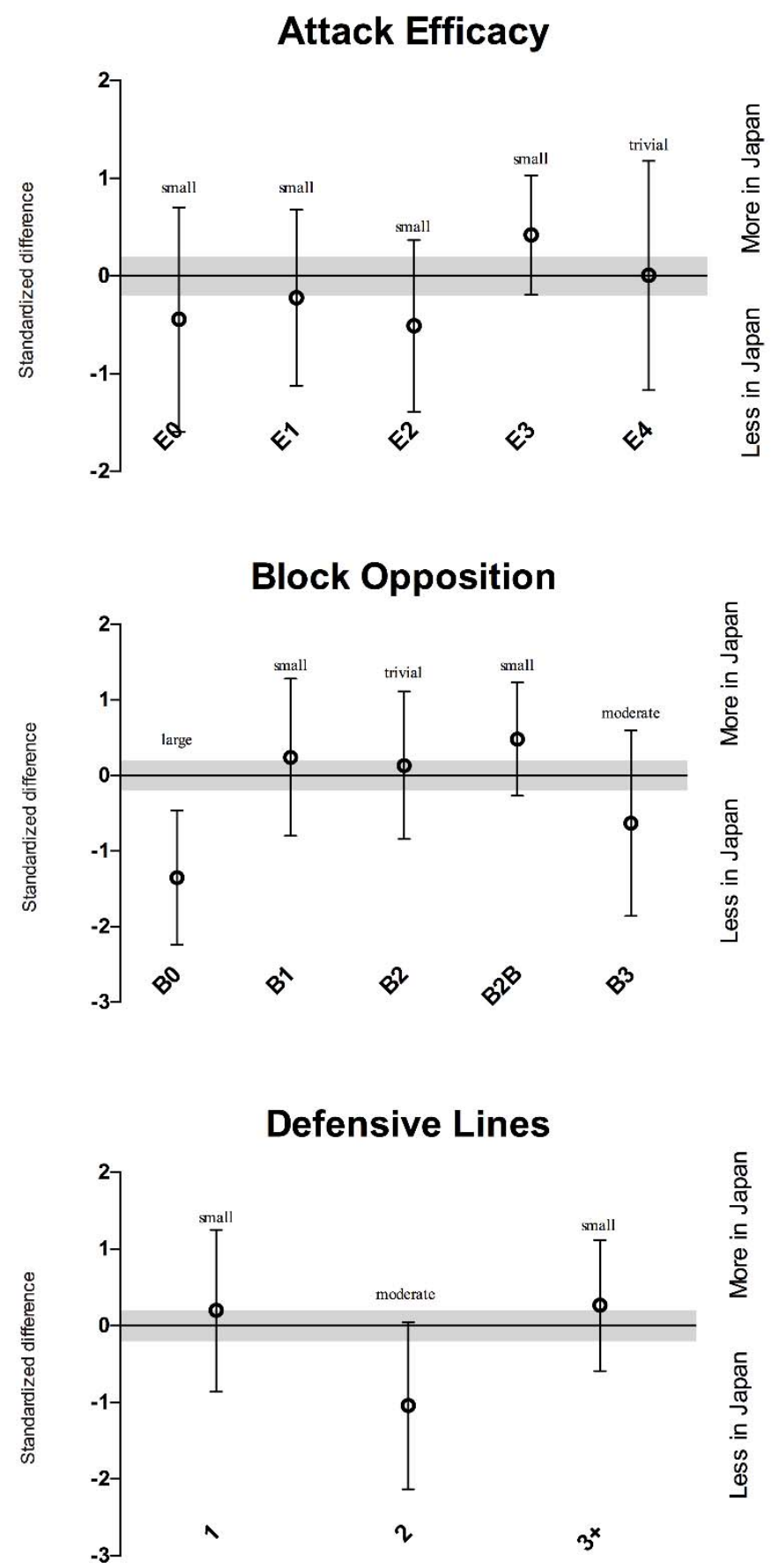

Figure 4

Attack efficacy, block opposition and defensive lines 


\section{Discussion}

Talent identification, development, and selection (TIDS) are pillars of the sports system, as this framework supposedly promotes the optimization of the sports preparation process (Pankhurst et al., 2013). However, mainstream TIDS proposals currently have to deal with two major inconsistencies (Ackerman, 2014). The first is that although research on expertise has shown that there are multiple possible paths to achieve high-level performance (Burgess and Naughton, 2010), TIDS programs usually consider physical and/or physiological features too prominently (Gonçalves et al., 2012). The second inconsistency arises internally, as research within the field of TIDS has been suggesting that psychosocial indicators may be more relevant for accomplishing high-level performance than physical indicators (Duckworth et al., 2007). Unfortunately, such theoretical perspectives are not being sufficiently incorporated into empirical research, and the search for physical and physiological predictors of performance remains paramount (Gonçalves et al., 2012). Even experienced coaches often fail to acknowledge the relevance of tactical and psychological aspects for performance (Millistetd et al., 2013). The time has come to perhaps reconsider the nature and type of predictors used for TIDS. A multiple-model approach is suggested, respecting the diversified paths to expertise and the inter- and intraindividual differences in features and in the rate of development (Duckworth et al., 2007).

Here, we focused on the Japanese Women's National Volleyball Team, since it figures consistently among the first ranked teams in the world, despite being substantially shorter than all other opponents at such level. We therefore attempted to identify game-related actions that assisted in establishing a difference between this team and their opponents in a highprofile international competition (World Grand Prix Finals of 2014). Hopefully, this would provide also relevant insights into how we frame and understand TIDS in this sport. Despite gameplay being a collective behavior, it might provide clues with regard to individual characteristics required to play in a certain way.

Indeed, our analyses revealed a number of differences between Japan's gameplay and the other teams' gameplay. Specifically, we found differences of very large magnitude for the serve type (higher likelihood of using the float jump serve, and lower for the ground serve and the power jump serve), serve trajectory (lower utilization of serves from position 5 towards position 6), and attack zone (with lower gameplays deploying attacks through zone 1). There were also differences in gameplay with large magnitude of effect, especially with regard to the serve trajectory (lower utilization of serves from position 5 towards position 5), attack tempo (higher utilization of tempo 2 and lower of tempo 1), and block opposition (lower likelihood of Japan using zero blockers when facing the opponent's attack). In addition, differences with moderate magnitude of effect were identified for the game complex (lower gameplays in complex III), setter's row (lower gameplays with the setter in the back row), attack zone (higher gameplays using zone 2), attack tempo (lower gameplays using tempo 3), attack combination (higher gameplays using simple attack plays, with lower utilization of the zone overload), and a number of defensive lines (with lower gameplays deploying two lines of defense). Finally, there were differences of small magnitude, namely in the game complex (higher gameplays in complex V), setter's zone (higher gameplays with the setter in the front row), and setting zone (higher gameplays with setting in zone A).

There are clear indications that the Japanese team shows distinct game patterns, moving away from the tendencies and patterns of the other top-level teams in selected game variables. As we selected only a handful of game variables, the possibility that additional differences exist in other game variables has to be considered. Perhaps herein lies part of the explanation behind Japan's success despite being one of the shortest teams playing at this level and being the most successful of that group with short teams. This reasoning seems to be in line with the notion that there are multiple paths to excellence, and that performance at the highest level of competition is compatible with different performance models (Ko et al., 2003). Consequently, TIDS models should consider multiple paths, even within the same sport and the same specific playing function (Vaeyens et al., 2009). In particular, such models should consider alternative paths to success when the main path is 
not realistic (e.g., when your team is clearly shorter in a sport where height is a very relevant factor).

Notwithstanding, can our results concerning high-level performance provide indicators as to which factors should be considered in TIDS? We believe so. First and foremost, eye-hand coordination, especially when combined with depth perception, may be of paramount importance. This has already been suggested by literature in the domain of motor learning (Neggers and Bekkering, 2002), but is seldom included in TIDS programs. The Japanese team has higher gameplay setting in zone $A$, denoting a superior quality of the first contact. Quality of the first contact is highly recognized as one of the most important aspects for achieving solid performance at the highest level of competitive volleyball (Costa et al., 2014), and research has been conducted relating the quality in this action with depth and trajectory perception, most notably in serve-reception (Papadimitriou et al., 2004). Therefore, perhaps TIDS programs in volleyball should consider analyzing the quality of serve-reception of players from young ages.

The ability to play under certain speed constraints also emerged as relevant. For example, Japan almost never gets into defensive situations with zero blockers, unlike the other teams. This implies a solid set of reading skills and movement speed that allow the Japanese blockers to always mount some type of opposition to the opponents' attacks. This suggests that specific reaction time (leading to proper decision-making in gamespecific contexts) is relevant (Nuri et al., 2013), and further denotes the need to generate habituation to quick attack plays. This perspective seems to be legitimated by the higher likelihood of Japan playing with tempo 2 and lower likelihood of using tempo 3. Overall, the team's attack plays are usually quicker, in average, than the opponents' plays (although the overall attack patterns are largely based on simple attack plays, without crossing or zone overloading). Thus, specific complex reaction time and speed of movements seem to emerge as relevant factors for consideration (Mroczek et al., 2013). Also, this reinforces the need to explore visual accuracy under dynamic settings, as faster attack balls produce trajectories that are more flattened and lower than slower ball trajectories; this will, in turn, imply differences in visual processing when preparing the attack (Afonso and Mesquita, 2007).

However, our data should be regarded as tentative, considering that they represent a case study limited to one National Team during one competition. Also, the developmental paths followed by each athlete and by the Japanese National Team as a whole were not analyzed. Therefore, this study can only a hint of a wider picture.

\section{Conclusion}

The objective of this research was to analyse an elite-level women's volleyball team that did not present the mainstream average height typical for performing at that level, and to disclose some game factors that could differentiate it from other, taller, teams. By doing so, we would further support the need for a multiple-pathway approach to TIDS. Specifically, with regard to volleyball performance, this study underlined the possibility of shorter teams still being able to perform at the highest competitive level. Notwithstanding an inferior stature, improving upon certain game variables might allow teams to still be amongst the elite. For example, greater likelihood of utilization of the float jump serve might present a good relationship between risk and precision, thereby conferring tactical advantage to the serving team. More frequent utilization of attack tempo 2 suggests that avoiding speed extremes, coupled with training for consistent tempo in attack, might confer some competitive edge. Furthermore, and although double blocking is attempted by most teams, a strategy based more strongly on individual blocking might be more consistent with shorter teams, especially as it guarantees that situations with zero blockers will not occur. Hence, coaches should first understand the characteristics of their teams, and then build a game model and training model surrounding those features, and not the other way around. All these conclusions should be considered tentative, due to the nature of this research.

Talent identification and/or detection programs attempt to optimize the development of future elite athletes. Notwithstanding, most of them tend to focus on a narrow group of variables, usually anthropometric and/or 
physiological. As we have shown, it is possible for a team to perform at the highest level even when lacking supposedly determinant features of a certain sport (e.g. height). This is not to state that the variables we analyzed are the key; indeed, we recognize they are a very small piece of the puzzle. It might even be that gameplay is only relevant when height is not sufficient, and a good gameplay may not exclude height from being an important variable. Furthermore, our study was observational, and therefore no causal links should be derived from our data. Still, evidence suggests that there are alternative routes to success, which should lead to criticism of unidimensional TIDS and promote the development of alternative working philosophies in order to obtain the best out of athletes and/or teams that lack certain anthropometric features. Our contribution is tentative and modest, and future studies should investigate whether our proposals might effectively predict elite performance and therefore be included in TIDS models.

\section{References}

Ackerman PL. Nonsense, common sense, and science of expert performance: Talent and individual differences. Intelligence, 2014; 45: 6-17

Afonso J, Mesquita I. Pilot study concerning the relationship between attack play and attack tempo in women's volleyball. Port J Sport Sci, 2007; 7: S46-47

Afonso J, Mesquita I. Determinants of block cohesiveness and attack efficacy in high-level women's volleyball. Eur J Sport Sci, 2011; 11: 69-75

Afonso J, Mesquita I, Marcelino R, Silva J. Analysis of the setter's tactical action in high-level women's volleyball. Kinesiol, 2010; 42: 82-89

Beunen GP, Malina RM, Freitas DI, Maia JA, Claessens AL, Gouveia ER, Lefevre J. Cross-validation of the Beunen-Malina method to predict adult height. Ann Hum Biol, 2010; 37: 593-597

Burgess DJ, Naughton GA. Talent development in adolescent team sports: A review. Int J Sports Physiol Perform, 2010; 5: 103-116

Cole TJ, Wright CM. A chart to predict adult height from a child's current height. Ann Hum Biol, 2011; 38: 662-668

Costa G, Afonso J, Brant E, Mesquita I. Differences in game patterns between male and female youth volleyball. Kinesiol, 2012; 44: 60-66

Costa GCT, Afonso J, Barbosa RV, Coutinho P, Mesquita I. Predictors of attack efficacy and attack type in high-level Brazilian women's volleyball. Kinesiol, 2014; 46: 242-248

Duckworth AL, Peterson C, Matthews MD, Kelly DR. Grit: perseverance and passion for long-term goals. J Pers Soc Psychol, 2007; 92: 1087-1101

Fleiss J, Levin B, Paik M. Statistical methods for rates and proportions. New Jersey, U.S.A.: John Wiley \& Sons; 2003

Gabbett T, Georgieff B, Domrow N. The use of physiological, anthropometric, and skill data to predict selection in a talent-identified junior volleyball squad. J Sports Sci, 2007; 25: 1337-1344

Gil A, Del Villar F, Moreno A, Moreno M, García-González L. Analysis of the efficacy of volleyball serve formation in category. Int J Med Sci Phys Activ Sport, 2011; 11: 721-737

Gonçalves CEB, Rama LML, Figueiredo AB. Talent identification and specialization in sport: An overview of some unanswered questions. Int J Sports Physiol Perform, 2012; 74: 390-393

Grasgruber P, Cacek J, Kalina T, Sebera M. The role of nutrition and genetics as key determinants of the positive height trend. Econ Hum Biol, 2014; 15: 81-100 
Hopkins WG, Marshall SW, Batterham AM, Hanin J. Progressive statistics for studies in sports medicine and exercise science. Med Sci Sports Exerc, 2009; 41: 3-12

Ko BG, Gu HM, Park DH, Back JH, Yun SW, Lee MC, Lee JG, Chang DS, Shin SY. The construction of sports talent identification models. Int J Appl Sports Sci, 2003; 15: 64-84

Kulasegaram KM, Grierson LEM, Norman GR. The roles of deliberate practice and innate ability in developing expertise: Evidence and implications. Med Educ, 2013; 47: 979-989

Laporta L, Nikolaidis P, Thomas L, Afonso J. The importance of loosely systematized game phases in sports: The case of attack coverage systems in high-level women's volleyball. Montenegrin J Sport Sci Med, 2015; 4: 19-24

Lehmann A, Kristensen F. "Persons in the Shadow" brought to light: Parents, teachers, and mentors-how guidance works in the acquisition of musical skills. Talent Dev Excell, 2014; 6: 57-70

Leite N, Baker J, Sampaio J. Paths to expertise in Portuguese national team athletes. J Sports Sci Med, 2009; 8: 560-566

Macnamara BN, Hambrick DZ, Oswald FL. Deliberate practice and performance in music, games, sports, education, and professions: A meta-analysis. Psychol Sci, 2014; 25: 1608-1618

Martín-Matillas M, Valadés D, Hernández-Hernández E, Olea-Serrano F, Sjöström M, Delgado-FernáNdez M, Ortega FB. Anthropometric, body composition and somatotype characteristics of elite female volleyball players from the highest Spanish league. J Sports Sci, 2014; 32: 137-148

Maszczyk A, Roczniok R, Waśkiewicz Z, Czuba M, Mikołajec K, Zajac A, Stanula A. Application of regression and neural models to predict competitive swimming performance. Percept Mot Skills, 2012; 114(2): 610-26

Millistetd M, Mesquita I, Sobrinho A, Carrara P, Nascimento J. Coaches representation about detection and selection of talents on the brazilian volleyball. Int J Sports Sci, 2013; 3: 157-162

Moesch K, Hauge M, Wikman J, Elbe A. Making it to the top in team sports: Start later, intensify, and be determined. Talent Dev Excell, 2013; 5: 85-100

Mroczek D, Kawczyński A, Superlak E, Chmura J. Psychomotor performance of elite volleyball players during a game. Percept Mot Skills, 2013; 117: 801-810

Neggers SFW, Bekkering H. Coordinated control of eye and hand movements in dynamic reaching. Hum Mov Sci, 2002; 21: 349-376

Nikolaidis PT, Afonso J, Busko K. Differences in anthropometry, somatotype, body composition and physiological characteristics of female volleyball players by competition level. Sport Sci Health, 2015a; 11: 29-35

Nikolaidis PT, Afonso J, Buśko K, Ingebrigtsen J, Chtourou H, Martin JJ. Positional differences of physical traits and physiological characteristics in female volleyball players - the role of age. Kinesiol, 2015b; 47: 75-81

Nuri L, Shadmehr A, Ghotbi N, Attarbashi Moghadam B. Reaction time and anticipatory skill of athletes in open and closed skill-dominated sport. Eur J Sport Sci, 2013; 13: 431-436

Palao J, Ahrabi-Fard I. Side-out success in relation to setter's position on court in women's college volleyball. Int J Appl Sports Sci, 2011; 23: 155-167

Palao JM, Santos JA, Ureña A. Effect of team level on skill performance in volleyball. Int J Perform Anal Sport, 2004; 4: 50-60

Pankhurst A, Collins D, Macnamara Á. Talent development: Linking the stakeholders to the process. J Sports Sci, 2013; 31: 370-380

Papadimitriou K, Pashali E, Sermaki I, Mellas S, Papas M. The effect of the opponents' serve on the offensive actions of Greek setters in volleyball games. Int J Perform Anal Sport, 2004; 4: 23-33 
Pion JA, Fransen J, Deprez DN, Segers VI, Vaeyens R, Philippaerts RM, Lenoir M. Stature and jumping height are required in female volleyball, but motor coordination is a key factor for future elite success. J Strength Cond Res, 2015; 29: 1480-1485

Sheppard JM, Dingley AA, Janssen I, Spratford W, Chapman DW, Newton RU. The effect of assisted jumping on vertical jump height in high-performance volleyball players. J Sci Med Sport, 2011; 14: 8589

Vaeyens R, Güllich A, Warr CR, Philippaerts R. Talent identification and promotion programmes of olympic athletes. J Sports Sci, 2009; 27: 1367-1380

\section{Corresponding author:}

\section{Pantelis T. Nikolaidis}

Address: Thermopylon 7, Nikaia 18450, Greece

Telephone: +306977820298

Fax: +302104907557

Email: pademil@hotmail.com 